\title{
Rhabdomyolysis Due to Severe Hypophosphatemia in Diabetic Ketoacidosis
}

\author{
Satish Kumar Shah,' Lokraj Shah,, Suraj Bhattarai, ${ }^{1}$ Megha Giri' \\ 'B.P. Koirala Institute of Health Sciences, Dharan, Nepal
}

\section{ABSTRACT}

Rhabdomyolysis(RM) is a syndrome characterized by injury to skeletal muscle fibers with disruption and release of toxic metabolites into circulation. It is characterized by triad of muscle weakness, myalgia and dark urine and is associated with increased creatine kinase (CK) and lactate dehydrogenase $(\mathrm{LDH})$.

A severely malnourished 10 year old girl with severe diabetic ketoacidosis (DKA) as hemr initial presentation of type 1 diabetes mellitus developed rhabdomyolysis (CK- 12,000 U/L) with nonoliguric renal failure during her initial course of hospital stay. The possible cause of her RM was attributed to severe hypophosphatemia (minimum serum phosphate, $0.8 \mathrm{mg} / \mathrm{dL}$ ). Management of DKA, phosphate supplementation and urinary alkalinization with diuresis improved her clinical course. She was discharged on Day 9 with Insulin.

We recommend frequent monitoring of serum phosphate during early period of DKA, particularly in malnourished children, and its normalization in case of severe hypophosphatemia.

Keywords: diabetic ketoacidosis; hypophosphatemia; malnutrition; renal failure; rhabdomyolysis.

\section{INTRODUCTION}

Rhabdomyolysis (RM) occurs following injury to the skeletal muscles leading to leakage of toxic intracellular components into plasma. It is characterized by triad of muscle weakness, myalgia and dark urine. It has many etiologies such as trauma, drugs, infections, metabolic abnormalities and genetic conditions. ${ }^{1}$ One must be alert to the diagnosis this condition, owing to its subtle presentation, to prevent acute renal failure.

We present a case of a 10 year old girl diagnosed with rhabdomyolysis in association with severe hypophosphatemia who presented with diabetic ketoacidosis (DKA). This is rare complication encountered in the management of DKA in a children. This might be important lesson to the readers regarding its management specially in malnourished children.

\section{CASE REPORT}

A previously healthy 10 year old girl from rural part of Eastern Nepal presented in the Emergency Department with chief complaints of excessive urination and excessive thirst for four days and altered sensorium for one day. Over the preceding week, she had fever, cough and upper respiratory tract symptoms for which she had visited primary health care service in her village and was prescribed oral antibiotics which brought some improvement. Review of systems was otherwise normal. There was no family history of diabetes.

On admission to Emergency Department, she was agitated, confused with GCS of $11 / 15$ (E3M5V3) and was severely dehydrated (sunken eyes, coated tongue and ketotic breath). Her blood pressure was $90 / 60 \mathrm{mmHg}$, pulse was feeble with rate of $120 /$ min, and respiratory rate of $28 / \mathrm{min}$. Chest was clear to auscultation, heart sounds were normal and there was no hepatosplenomegaly. Tendon reflexes were sluggish bilaterally. She was severely malnourished with weight of $18 \mathrm{~kg}$ (w/a z score <-3) and BMI of 13

Correspondence: Dr Satish Kumar Shah, Department of Pediatrics, Department of Pediatrics, BPKIHS, Dharan, Nepal. Email: drsatishshah@ hotmail.com, Phone: $+977-9813638077$. 
(BMI for age z score <-3). Admission laboratory values showed hyperglycemia $(620 \mathrm{mg} / \mathrm{dL})$, severe acidosis $(\mathrm{pH}=6.91 ; \mathrm{HCO} 3=5.2 \mathrm{meq} / \mathrm{L})$ and urine ketones. Impression of Diabetes with Ketoacidosis was made and was managed for the same. $\mathrm{HbA} 1 \mathrm{C}$ was $12.0 \%$.

In view of shock, the child received Normal Saline bolus $(20 \mathrm{ml} / \mathrm{Kg})$ and dopamine infusion (10mcg/ $\mathrm{kg} / \mathrm{min}$ ) in ED and was transferred to Intensive Care Unit for further management. Patient was started on rehydration therapy with $0.9 \% \mathrm{NS}$ at $70 \mathrm{ml} / \mathrm{hr}$ for next 48 hour. Regular Insulin infusion was started at $0.1 \mathrm{U} /$ $\mathrm{kg} / \mathrm{hr}$. Inj KCL was added to the fluid at $40 \mathrm{meq} / \mathrm{L}$ after documenting initial potassium of $3.5 \mathrm{meq} / \mathrm{L}$. Urinary catheterization was done to monitor shock.

Six hour after initiating therapy, her blood sugar dropped to $420 \mathrm{mg} / \mathrm{dL}$ with subtle improvement in acidosis $(\mathrm{pH}=7.1)$. There was slight improvement in sensorium. However, at $8^{\text {th }}$ hour of PICU stay, patient developed dark/cola colored urine which over the next few hours became darker. There was no deterioration in hemodynamics and sensorium status, but there was some difficulty in moving her limbs. There was no tenderness in her limbs.

In view of child's dark colored urine, a possibility of hematuria due to probable traumatic urethral catheterization was thought and thus urine microscopy examination was sent. However, urine did not show any Red Blood Cells. To reconfirm, urine was tested on dipstick which showed blood but no RBCs. Thereupon serum creatine kinase (CK) was sent which was found to be highly increased $(12,000 \mathrm{U} / \mathrm{L}$; normal $<150$ $\mathrm{U} / \mathrm{L})$. Serum Lactate dehydrogenase (LDH), Aspartate transaminase (AST) and Alanine transaminase (ALT) were also elevated [ LDH, $1150 \mathrm{U} / \mathrm{L}$ (normal, 200-500 $\mathrm{U} / \mathrm{L}$ ); AST, $245 \mathrm{U} / \mathrm{L}$ (normal 5-40 U/L); ALT, $250 \mathrm{U} / \mathrm{L}$ (normal 5-40 U/L)] (Table 1). Thus a possibility of RM was considered.

\begin{tabular}{|c|c|c|c|c|c|c|c|c|}
\hline Variables & Admission & $8 \mathrm{hr}$ & $16 \mathrm{hr}$ & $24 \mathrm{hr}$ & Day 3 & Day 4 & Day 5 & Day 7 \\
\hline $\begin{array}{l}\text { Glucose } \\
\text { (mg/dL) }\end{array}$ & 620 & 400 & 380 & 162 & 124 & 112 & 136 & 118 \\
\hline $\mathrm{pH}$ & 6.91 & 7.10 & 7.12 & 7.16 & 7.31 & - & 7.35 & - \\
\hline $\begin{array}{l}\mathrm{HCO} 3 \\
(\mathrm{meq} / \mathrm{L})\end{array}$ & 5.2 & 6.8 & 12.2 & 15.2 & 16.2 & - & 20.4 & - \\
\hline Urine RE & $\begin{array}{l}\text { Ketone + ; } \\
\text { no RBCs }\end{array}$ & $\begin{array}{l}\text { Ketone + ; } \\
\text { no RBCs }\end{array}$ & - & - & $\begin{array}{l}\text { Ketone +; no } \\
\text { RBCs }\end{array}$ & - & - & - \\
\hline $\mathrm{Na}$ (meq/L) & 118 & 122 & - & 134 & 137 & - & - & - \\
\hline $\mathrm{K}$ (meq/L) & 3.5 & 3.2 & - & 3.6 & 4.0 & - & - & - \\
\hline $\begin{array}{l}\text { Phosphate } \\
\text { (mg/dL) }\end{array}$ & - & 0.8 & - & 2.9 & - & 3.0 & - & - \\
\hline FePO4 (\%) & - & 52 & - & 28 & - & - & - & - \\
\hline $\mathrm{Hb}(\mathrm{mg} / \mathrm{dL})$ & 10.2 & 9.8 & - & - & - & 10.2 & - & - \\
\hline $\operatorname{TLC}\left(/ \mathrm{mm}^{3}\right)$ & 23,300 & 18,800 & - & - & - & 14,400 & - & - \\
\hline $\begin{array}{l}\text { Platelet (/ } \\
\mathrm{mm}^{3} \text { ) }\end{array}$ & 280,000 & 300,000 & - & - & - & 320,000 & - & - \\
\hline $\begin{array}{l}\text { Creatinine } \\
(\mathrm{mg} / \mathrm{dL})\end{array}$ & 0.9 & 0.8 & - & 1.4 & 1.3 & 1.1 & 0.9 & - \\
\hline Urea(mg/dL) & 54 & 82 & - & 96 & 92 & 84 & 62 & - \\
\hline CK (U/L) & - & 12,000 & & 10,400 & & 5,400 & - & 640 \\
\hline $\begin{array}{l}\text { Fluids and } \\
\text { medication }\end{array}$ & $\mathrm{NaCl} 0.9 \%$ & $\begin{array}{l}\mathrm{NaCl} 0.9 \%+ \\
\mathrm{NaHCO} 3 \\
\text { (2ampoules/L) } \\
\text { + Mannitol } \\
\text { + Enteral } \\
\text { Phosphate }\end{array}$ & $\begin{array}{l}\mathrm{NaCl} 0.9 \% \\
+\mathrm{NaHCO} 3 \\
\text { (2 } \\
\text { ampoules/L) } \\
\text { + Mannitol } \\
\text { + Enteral } \\
\text { Phosphate }\end{array}$ & $\begin{array}{l}\mathrm{NaCl} 0.45 \% \\
+\mathrm{D} 5+ \\
\mathrm{NaHCO} 3 \\
\text { (2ampoules/L) } \\
+ \text { Mannitol } \\
+ \text { Enteral } \\
\text { Phosphate }\end{array}$ & $\begin{array}{l}\mathrm{NaCl} 0.45 \% \\
+\mathrm{D} 5+ \\
\mathrm{NaHCO} 3 \\
\text { (2ampoules/L) } \\
+ \text { Mannitol } \\
+ \text { Enteral } \\
\text { Phosphate }\end{array}$ & $\begin{array}{l}\text { Oral } \\
\text { feeds }\end{array}$ & - & - \\
\hline
\end{tabular}


Next step was to find the possible etiology of RM. Throat swab for influenza was negative; serum phosphate and potassium were $0.8 \mathrm{mg} / \mathrm{dL}$ (normal $2.5-5.0 \mathrm{mg} / \mathrm{dL}$ ) and $3.2 \mathrm{meq} / \mathrm{L}$ respectively. Urinary phosphate excretion was highly increased up to $52 \%$ (normal $<20 \%$ ).

Thus for severe hypophosphatemia, patient was started on enteral phosphate at $50 \mathrm{mg} / \mathrm{kg} / \mathrm{day}$ (Intravenous phosphate preparation was not available in the country). Despite the evidence of acute kidney injury in the form of increased urea and creatinine (table 1), patient was not started on any form of renal replacement therapy because her urine output was fairly normal. However, to prevent further renal damage due to RM, child was started on urinary alkalization with Sodium bicarbonate ( 2 ampoules/L of IV fluid) and Mannitol for total of four doses.

Over the next three days, urine color gradually normalized to baseline. Ketoacidosis and sensorium also normalized on day three. The patient was then switched to subcutaneous insulin on day four. Repeat serum phosphate on day four was $3.0 \mathrm{mg} / \mathrm{dL}$. Nutritional rehabilitation was done. Patient was discharged on day nine at total insulin dose of $0.9 \mathrm{U} / \mathrm{Kg} / \mathrm{d}$.

After three months, her $\mathrm{HbA} 1 \mathrm{C}$ was $8.2 \%$ with intact neurological examination. Autoantibody for Type 1 DM, and serum and urine myoglobin levels could not be tested due to unavailability of these tests at the centre.

\section{DISCUSSION}

The patient described here presented at ED with DKA as the initial presentation of T1DM. However, her clinical course was complicated by RM with non-oliguric renal failure. The possible cause attributed for her RM was severe hypophosphatemia. The cause of RM can be multiple, ranging from viral etiologies to mechanical trauma and various metabolic causes. ${ }^{1}$ Since our resources were limited to do the complete workup to find out the cause of RM, we believed that it might be due to severe hypophosphatemia considering the fact that after correcting serum phosphate, patient's clinical features gradually subsided and she eventually improved.

Although hypophosphatemia is common in DKA, it is rarely very severe leading to the complications. Prolonged profound ketoacidosis with insulin infusion in the initial rehydration phase can lead to severe hypophosphatemia, mainly due to intracellular shifting of the phosphate. ${ }^{2,3}$ Additionally, prolonged acidosis can lead to decreased proximal tubular phosphate reabsorption which further leads to increased excretion of phosphate resulting in severe hypophosphatemia. ${ }^{4}$
Besides that severe undernutrition and malnourished status also creates the state of inadequate serum phosphate in children. ${ }^{5}$ Our patient was severely malnourished probably due to undetected T1DM and being from the poor socioeconomic background. Severe malnutrition may have led to her decreased body phosphate level which probably got further aggravated by decreased reabsorption due to prolonged acidosis and to some extent intracellular shift due to insulin infusion. We could clearly document increased excretion of phosphate in this case. Therefore in the setting of severe malnutrition in DKA we suggest frequent monitoring of serum phosphate.

The mechanism leading to RM in DKA is unclear. Zierler has shown that an alteration of electrolytes and glucose in the incubation medium in the presence of insulin can lead to leakage of intracellular enzymes from an isolated in vitro muscle preparation. ${ }^{6}$ Other factors that play role in the development of RM are depletion of potassium and phosphate. Regardless of the causes of RM, the common mechanism is disruption of sarcolemma and release of intracellular myocyte component.

Phosphate is one of the constituents of adenosine triphosphate (ATP) and in case of severe hypophosphatemia, there is ATP depletion which leads to cellular injury and then rhabdomyolysis. ${ }^{7}$

Acute Kidney Injury (AKI) is a dreadful complication of rhabdomyolysis and is reported in $15-30 \%$ of rhabdomyolysis patient. ${ }^{8,9} \mathrm{AKI}$ is believed to be triggered by myoglobin as a toxin causing renal dysfunction [10]. In our case, patient developed non-oliguric renal failure but did not require any form of renal replacement therapy. Hypophosphatemia leading to rhabdomyolysis in DKA has been reported by various authors with or without significant renal failure requiring renal replacement therapy. ${ }^{11-15}$

Phosphate replacement in DKA is still controversial with no clear cut guideline. ${ }^{16}$ We supplemented our patient with enteral phosphate due to severe hypophosphatemia. As a result, serum phosphate gradually increased and rhabdomyolysis subsequently decreased.

General management of rhabdomyolysis includes fluid resuscitation and prevention of ARF. ${ }^{1}$ Accordingly, we increased the fluid and, to prevent ARF, urinary alkalinization was done using Sodium bicarbonate. It is believed that acidic urine is responsible for acute tubular necrosis. Mannitol was also used to increase the urinary flow thus preventing myoglobin cast obstruction in renal tubule.

In conclusion our patient developed RM, severe hypophosphatemia with non-oliguric renal failure associated with DKA which gradually got resolved 
by urinary alkalinization, phosphate replacement and diuresis with mannitol. Thus, serum phosphate should be frequently measured during management of DKA. Hypophosphatemia rarely causes RM, but it must be anticipated in case of severe hypophosphatemia especially in the setting of severe malnutrition. Once RM has occurred, appropriate measures should be taken to preserve renal function.

\section{ACKNOWLEDGEMENTS}

We highly acknowledge the administration of BPKIHS, their department of Pediatrics and Adolescent Medicine, and the Staff and residents involved in the treatment of this case.

\section{REFERENCES}

1. Bagley $\mathrm{WH}$, Yang $\mathrm{H}$, Shah $\mathrm{KH}$. Rhabdomyolysis. Intern Emerg Med. 2007;2:210-8.

2. Riley MS, Schade DS, Eaton RP. Effects of insulin infusion on plasma phosphate in diabetic patients. Metabolism.1979;28:191-4.

3. Kebler R, McDonald FD, Cadnapaphornchai P. Dynamic changes in serum phosphorus levels in diabetic ketoacidosis. Am J Med. 1985;79:571-6.

4. Busch A, Waldegger S, Herzer T, Biber J, Markovich D, Hayes G, et al. Electrophysiological analysis of $\mathrm{Na}+/ \mathrm{Pi}$ cotransport mediated by a transporter cloned from rat kidney and expressed in Xenopus oocytes. Proc Natl Acad Sci USA, 1994;91:8205-8.

5. Yoshimatsu S, Hossain MI, Islam MM, Chisti MJ, Okada $\mathrm{M}$, et al. Hypophosphatemia among severely malnourished children with sepsis in Bangladesh. Pediatr Int. 2013;55:79-84.

6. Zierler K, Increased muscle permeability to aldolase produced by depolarization and by metabolic inhibitors. Am J Physiol. 1958;193:534-40.

7. Mannix R, Tan ML, Wright R, Baskin M. Acute pediatric rhabdomyolysis: causes and rates of renal failure. Pediatrics. 2006;118:2119-25.

8. Vanholder R, Sever MS, Erek E, Lameire N. Rhabdomyolysis. J Am Soc Nephrol. 2000;11:1553-61.

9. Sauret JM, Marinides G, Wang GK, Rhabdomyolysis. Am Fam Physician. 2002;65:907-12.
10. Nath KA, Balla G, Vercelloti GM, Balla J, Jacob HS, Levitt $\mathrm{MD}$, et al. Induction of heme oxygenase is a rapid, protrective response in rhabdomyolysis in the rat. J Clin Invest. 1992;90:267-70.

11. Casteels K, Beckers D, Wouters C, Van GeetC. Rhabdomyolysis in diabetic ketoacidosis. Pediatr Diabetes. 2003;4:29-31.

12. Singhal PC, Abramovici M, Venkatesan J. Rhabdomyolysis in the hyperosmolal state. Am J Med. 1990;88:9-12.

13. Li W, Gong C, Wu D, Liu M. Two case reports of severe pediatric hyperosmolar hyperglycemia and diabetic ketoacidosis accompanied with rhabdomyolysis and acute renal failure. J Pediatr Endocrinol Metab. 2014;27:1227-31.

14. Al-Matrafi J, Vethamuthu J, Feber J. Severe acute renal failure in a patient with diabetic ketoacidosis. Saudi J Kidney Dis Transpl. 2009;20:831-4.

15. Kutlu A, Kara C, Cetinkaya S. Rhabdomyolysis Without Detectable Myoglobulinuria Due to Severe Hypophosphatemia in Diabetic Ketoacidosis. Pediatr Emerg Care. 2011;27:537-38.

16. Amanzadeh J, Reilly RF. Hypophosphatemia: an evidencebased approach to its clinical consequences and management. Nat Clin Pract Nephrol. 2006;2:136-48. 